\title{
Percutaneous Endoscopic Gastrostomy
}

National Cancer Institute

\section{Source}

National Cancer Institute. Percutaneous Endoscopic Gastrostomy. NCI Thesaurus. Code C106040.

The placement of a feeding tube through the abdominal wall into the stomach using an endoscope. 